\title{
Interações verbais e não-verbais entre mães-crianças portadoras de Síndrome de Down e entre mães-crianças com desenvolvimento normal $^{1}$
}

\author{
Maria dos Prazeres Vieira da Silva \\ Nádia Maria Ribeiro Salomão \\ Universidade Federal da Paraiba
}

\begin{abstract}
Resumo
O presente estudo teve como objetivo analisar as interações entre mães-crianças portadoras de síndrome de Down (SD) e entre mães-crianças com desenvolvimento normal, enfatizando-se os aspectos comunicativos. Participaram dois grupos: seis díades mães-crianças portadoras de SD, com idade entre 18 e 24 meses e seis díades mães-crianças com desenvolvimento normal, com idade entre 12 e 14 meses. Os dados foram coletados nas residências das díades, através de sessões de observações, registradas em vídeo-tape. Os resultados mostraram que, para ajudar os filhos a realizarem atividades, as mães das crianças portadoras de SD usaram o contato físico mais do que as mães das crianças com desenvolvimento normal. As crianças portadoras de SD responderam menos às solicitações verbais de suas mães do que as crianças com desenvolvimento normal. Tais resultados foram discutidos considerando-se suas implicações para o contexto interativo mãe-criança e para a aquisição da linguagem.
\end{abstract}

Palavras-chave: Interação,Síndrome de Down,Linguagem.

\begin{abstract}
Mother-child verbal and non-verbal interactions in children with Down Syndrome and with normal development. The present study investigated mother-child interactions in children with Down Syndrome and with normal development, considering the communicative aspects. In this study, two groups participated: six dyads mother-child with Down Syndrome, age between 18 and 24 months and six dyads mother-child with normal development, age between 12 and 14 months. The dyads were videotaped in their homes. The results indicated that the mothers of the children with Down Syndrome used more physical contact to help the children accomplish their activities, than the mothers of children with normal development. The children with Down Syndrome answered less to the mothers' verbal solicitations than the children with normal development. The results are discussed considering the implications for the mother-child interactive context and for language acquisition.
\end{abstract}

Key words: Interaction, Down Syndrome, Language.

$\mathrm{E}$ ste trabalho foi fundamentado na Perspectiva da Interação Social dos estudiosos da linguagem, uma vez que, nesta abordagem, são considerados tanto a influência dos aspectos inatos para a aquisição da linguagem quanto dos aspectos comunicativos da linguagem, sendo enfatizada a interação social e o seu caráter sócio-cultural como promotor da construção de significados e da coordenação de papéis pelos indivíduos em interação.

A interação social assume o envolvimento ativo dos participantes, trazendo-lhes experiências diferentes e conhecimentos qualitativos e quantitativos (Garton, 1992). No caso da criança, existem oportunidades amplas para que ela possa interagir com outras pessoas. Dependendo da cultura e de outras convenções sociais, a criança tem graus variados de contato social com as pessoas, e cada pessoa terá algum tipo de influência sobre ela. Segundo Garton (1992), há inúmeras ocasiões em que as crianças se ocupam de interações sociais ativas, e essas oportunidades são fundamentais para o desenvolvimento de habilidades lingüísticas, cognitivas e de conhecimentos. Para este autor, o envolvimento da criança, na interação, deve ser ativo, pois é a contribuição desta e a participação da outra pessoa que determinam a natureza e o 
resultado da interação. Essa contribuição depende dos níveis de experiência e conhecimento existentes como também da natureza e do propósito da interação. A idade em que a criança se encontra, a linguagem existente e o conhecimento cognitivo poderão influenciar a natureza e a extensão da contribuição por ela dispensada. O contexto e a função da interação social também determinarão o papel adotado pelo participante e suas contribuições. Estas afirmações são compartilhadas pelos estudiosos da linguagem, como por exemplo, Snow (1997), que destaca a importância do ambiente e da interação social, sendo o input, apresentado pelos adultos, principalmente pelas mães, fundamental para o processo de aquisição e desenvolvimento das habilidades linguiísticas.

Para Snow (1972,1997), o input dirigido às crianças que estão aprendendo a linguagem constitui uma fala simples, mais limitada em vocabulário, mais correta e mais fluente, com entonações exageradas e ritmo diminuído. Essa fala especial é utilizada principalmente pelas mães e difere da fala direcionada aos adultos, ajustando-se semanticamente ao nível de compreensão e interesse da criança e promovendo a sintonia entre a mãe e o bebê, já que este parece ser mais responsivo a esse tipo de fala. Segundo Snow (1997), a entonação exagerada da fala do adulto representa uma resposta aos padrões de atenção dos bebês, pois eles demonstram preferência pelos enunciados mais agudos, respondendo com vocalizações e sorrisos.

Esse processo de ajuste entre a fala do adulto e o nível de compreensão da criança foi destacado em vários estudos. No estudo realizado por Conti-Ramsden e Friel-Patti (1986), por exemplo, no qual foi observada a complexidade cognitiva do diálogo entre mães e crianças de 12 a 24 meses, foi verificado que as mães se comunicavam no nível de compreensão das crianças e, ao mesmo tempo, em um nível mais complexo do que o nível a que as crianças respondiam efetivamente. As mães produziam expressões vocais que estavam um pouco além da competência das crianças. Dessa forma, a aprendizagem da fala era beneficiada, por um lado, porque a compreensão era facilitada pelas expressões vocais que tinham um nível de complexidade próximo do da criança. Ao mesmo tempo, a conexão entre o nível simples de expressão da criança e o modelo mais sofisticado era aumentada rapidamente com as expressões mais complexas, havendo, assim, uma correspondência entre o nível das expressões vocais iniciadas freqüentemente pelas crianças e o nível aos quais elas respondiam melhor.

A fala dirigida à criança apresenta outros aspectos que podem facilitar a interação adulto-criança e promover o desenvolvimento infantil. Um desses aspectos é o feedback, que diz respeito à resposta do adulto aos enunciados da criança. Os estudos realizados por Demetras, Post e Snow (1986) e Bohannon e Stanowicz (1988) mostraram que os adultos tendiam a responder diferentemente aos enunciados bem elaborados e aos mal elaborados pelas crianças. No caso dos primeiros, as mães geralmente davam prosseguimento ao tópico enunciado pela criança. Em relação aos enunciados mal elaborados, ou as mães os repetiam, atribuindo-lhes correções, ou solicitavam clarificação da criança, indicando para ela que o seu enunciado não estava claro. Também se verificou que os adultos tendem a responder os erros lingüísticos das crianças com correções gramaticais específicas, principalmente quando a expressão vocal da criança apresenta apenas um erro.

Braz (2000) também verificou o uso de feedbacks pelas mães em interação com seus filhos. Essa autora observou que as mães utilizaram feedbacks de aprovação, desaprovação e correção, não apenas para corrigir os enunciados de seus filhos, considerados incorretos do ponto de vista gramatical, mas ao dar esses tipos de feedback, elas também consideravam a precisão nas respostas dos filhos e a veracidade no conteúdo dessas respostas.

Para Aimard (1998), o feedback dispensado às crianças, principalmente pelas mães, favorece o desenvolvimento da linguagem porque possibilita à criança estruturar a construção lexical.

Outro aspecto da interação mãe-criança, que tem sido apontado como sendo promotor de desenvolvimento lingüístico, é a atenção conjunta. Segundo Akthar, Dunham e Dunham (1991), as mães podem fazer uso dos comportamentos não-verbais de seus bebês, como gestos e direção do olhar, para manter a atenção conjunta em um determinado evento durante as interações. Segundo esses autores, períodos de atenção conjunta entre pais e filhos podem ser benéficos para o desenvolvimento da linguagem porque representam o momento em que a criança está mais atenta e motivada para processar a fala dos pais.

Autores como Bruner (1980), Barrett (1997), Tomasello e Todd (1983) também destacam a importância da atenção conjunta para a aquisição e o desenvolvimento lingüísticos, pois favorece a negociação dos procedimentos adequados pelos parceiros para regular suas intenções nas interações, e contribui com a construção de significados, à medida que os parceiros compartilham atividades.

Os estudos realizados sobre interação social e desenvolvimento lingüístico têm mostrado que existem padrões de estilo da fala materna que são característicos, dependendo da idade da criança, de sua capacidade cognitiva e de seu desenvolvimento lingüístico, e que há, portanto, diferença entre os estilos de fala da mãe em relação à criança com desenvolvimento normal e à criança atípica. Essas diferenças podem se dever ao fato de que, nas crianças atípicas, as habilidades cognitivas e as capacidades lingüísticas estão menos interligadas do que nas crianças com desenvolvimento normal (Chapman,1997), fazendo com que elas participem menos das interações, o que pode influenciar o input materno.

Há, entretanto, controvérsias entre os resultados encontrados nos estudos sobre interações mães-crianças atípicas. Alguns autores (por exemplo, Buium, Rynders \& Turnure, 1974; Cunningham, Reuler, Blackwell \& Deek, 1981) alegam que a fala dirigida a crianças atípicas é mais diretiva e menos contextualizada semanticamente do que a fala dirigida a crianças com desenvolvimento normal. Outros (por exemplo, Conti-Ramsden \& Dykins, 1991; Salomão \& Conti-Ramsden, 1994; Salomão, 1996) afirmam que as mães tentam ajustar sua fala de acordo com o desenvolvimento lingüístico da criança 
e, portanto, são as características da criança que provocam certas mudanças na fala materna.

Em relação à fala dirigida à criança portadora de síndrome de Down, o ajuste da fala materna à fala infantil tem sido demonstrado por vários estudos, como por exemplo, o estudo realizado por Fischer (1987), no qual foi observado que as tentativas de interação social das crianças portadoras de síndrome de Down foram menos espontâneas. A maior parte dos sinais de comunicação apresentados por essas crianças foi eliciada pelas mães, e não iniciada pelos filhos. Este autor observou também que, apesar de as crianças portadoras de síndrome de Down serem menos responsivas, as mães responderam imediatamente aos seus sinais de comunicação com uma maior freqüência do que as mães do grupo controle.

Buckhalt, Rutherford e Goldberg (1978) também destacaram esse ajuste quando compararam as interações verbais e não-verbais entre dez mães e seus filhos portadores de síndrome de Down e dez mães e seus filhos com desenvolvimento normal. Esses autores observaram que as mães de ambos os grupos responderam com uma complexidade linguiística apropriada às solicitações dos filhos e que tais resultados refletiam ajustes previsíveis da fala que os adultos fazem, conforme percebem a competência da criança.

Estes ajustes foram observados também em relação às expressões afetivas. Cicchetti e Sroufe (1976) realizaram um estudo para investigar a relação entre desenvolvimento afetivo e cognitivo em crianças portadoras de síndrome de Down e constataram que essas crianças tinham reações afetivas pouco expressivas, ou seja, elas apenas sorriam a estímulos que eliciavam gargalhadas em bebês normais e, raramente choravam ou demonstravam medo frente a eventos indutores desse tipo de emoção. Segundo esses autores, tais resultados sugerem que crianças portadoras de síndrome de Down apresentam déficits básicos ao reagirem a eventos ambientais, o que pode levar as mães a se acomodarem aos baixos níveis de excitabilidade dos filhos, gerando um contexto menos estimulador durante a interação.

Assim, os resultados dos estudos que compararam as interações entre mães e crianças atípicas e entre mães e crianças com desenvolvimento normal vêm reforçar a necessidade de uma análise bidirecional quando se estuda a interação mãe-criança, como também a necessidade de maior atenção ao contexto no qual a criança está envolvida.

Tendo em vista esses aspectos, pretende-se, com este estudo, uma maior compreensão dos estilos comunicativos presentes nas interações entre mães e crianças e das implicações desses estilos para o processo de aquisição da linguagem inicial, sendo o principal objetivo analisar as interações entre mães e crianças portadoras de síndrome de Down e com desenvolvimento normal, enfatizando-se os aspectos comunicativos verbais e não-verbais.

\section{Método}

\section{Participantes}

Esta pesquisa foi realizada, com dois grupos: seis díades mães-crianças portadoras de síndrome de Down (SD) e seis díades mães-crianças com desenvolvimento normal. As características dos participantes estão discriminadas nos Quadros 1 e 2 do Apêndice A. As crianças portadoras de SD estavam integradas ao programa de estimulação precoce da FUNAD (Fundação e Centro Integrado de Apoio ao Portador de Deficiência), em João Pessoa - PB.

Para a avaliação do desenvolvimento das crianças e a equiparação dos grupos, foi utilizado o Baby-teste Brunet e Lézine (1981). Este instrumento é composto por dez itens, que são atribuídos por nível, de acordo com a idade da criança. O nível utilizado neste estudo corresponde à idade de 12 meses. A partir dos aspectos do desenvolvimento infantil, observados através do Baby-teste Brunet e Lézine, foram estabelecidas como critério de seleção das crianças, as idades de 12 a 14 meses, para as crianças com desenvolvimento normal, e de 18 a 24 meses, para as crianças portadoras de SD.

\section{Procedimento}

$\mathrm{O}$ contato com as mães das crianças portadoras de SD ocorreu através da FUNAD (Fundação e Centro Integrado de Apoio ao Portador de Deficiência). Com as mães das crianças com desenvolvimento normal, o contato foi feito por intermédio da creche da UFPB e através de amigos. No primeiro contato com as mães, foi explicado o objetivo da pesquisa e entregue uma correspondência solicitando a participação delas no estudo, assegurando-lhes o sigilo quanto às informações coletadas.

As observações das interações mães-filhos foram realizadas nas residências dos participantes, através de sessões de filmagens, em situação de brinquedo livre. Esta situação possibilita trocas interativas mais espontâneas e naturais, favorecendo assim a observação de interações mais semelhantes às que ocorrem no cotidiano das díades. Cada sessão de filmagem teve a duração de 20 minutos e foi realizada no ambiente da casa que ofereceu maior privacidade.

Para este estudo, foram utilizados apenas os dez primeiros minutos de cada filmagem, os quais foram codificados e analisados através do sistema computacional CHILDES (Child Language Data Exchange System). O CHILDES é um programa composto por três componentes principais: o banco de dados CHILDES, o sistema de transcrição CHAT e os programas CLAN.

O banco de dados CHILDES abrange uma grande variedade de amostras de linguagem de uma ampla gama de idades e situações. Todos os dados do banco de dados CHILDES representam interações espontâneas reais em contextos naturais (MacWhinney, 1997).

O sistema de transcrição CHAT (Codes for Human Analysis of Transcripts) é um sistema de codificação ou transcrição de dados que possui uma série de opções avançadas que permitem ao pesquisador obter níveis crescentes de precisão na transcrição e codificação de dados.

O CLAN (Computerised Language Analysis) é composto por programas de análise que, segundo MacWhinney (1997, p.138), foram elaborados para dar suporte a cinco tipos básicos de análises linguísticas: análise lexical, análise morfológica, análise sintática, análise do discurso e análise 
Tabela 1

Estilos de fala e ações das mães durante a interação com seus filhos.

\begin{tabular}{lccc}
\hline $\begin{array}{c}\text { Estilos de fala e ações } \\
\text { maternas }\end{array}$ & $\begin{array}{c}\text { Crianças portadoras de } \\
\text { Síndrome de Down } \\
\text { (Média de Postos) }\end{array}$ & $\begin{array}{c}\text { Crianças } \\
\text { normais } \\
\text { (Média de Postos) }\end{array}$ & Teste U \\
\hline Diretivos (geral) & 7,00 & 6,00 & 15,000 \\
Requisição (geral) & 5,33 & 7,67 & 11,000 \\
Feedback (geral) & 7,08 & 5,92 & 14,500 \\
Informação (geral) & 5,33 & 7,67 & 11,000 \\
Contato fisico de ajuda & 9,08 & 3,92 & $2,500^{* *}$ \\
Comentários & 6,17 & 6,83 & 16,000 \\
Demonstração de afeto & 6,50 & 6,50 & 18,000 \\
Outros & 6,25 & 6,75 & 16,500 \\
\hline
\end{tabular}

Nota: ${ }^{* *} \mathrm{p}<.01$

fonológica. Dessa maneira, o CLAN pode oferecer diversos componentes que favorecem o exame das estruturas das interações e das narrações.

A partir do formato de transcrição CHAT, as observações das interações mães-crianças deste estudo foram codificadas e analisadas através do CLAN, que permitiu uma análise mais precisa.

\section{Análise dos dados}

Para a análise das observações, foram transcritas todas as filmagens e, a partir das transcrições, foi feito um levantamento de várias categorias (Apêndice B). Para o levantamento foram consideradas a análise das filmagens e a literatura existente, através dos trabalhos de Nunes, Cunha e Nogueira (1993), Pine (1992), Salomão e Conti-Ramsden (1994). Com uma leitura minuciosa dos protocolos, decidiu-se fazer uma análise qualitativa complementar, na qual observaram-se as sequiências interativas com o intuito de verificar as iniciativas de interação por parte dos membros das díades. O levantamento das sequiências foi feito com base na definição de Sigolo (1996), em que sequiência interativa é entendida como uma seqüência de comportamentos desenvolvida entre os membros da díade que se alternam em, pelo menos, uma emis- são e uma resposta referentes a um mesmo tema. Para identificar o início e o término de cada sequiência, foram considerados tanto as verbalizações quanto os comportamentos nãoverbais dos participantes (Apêndice C).

Após a categorização das observações, $20 \%$ dos dados foram submetidos à análise, por outro pesquisador, para a verificação do índice de concordância quanto à aplicação das categorias aos enunciados e comportamentos das díades. Foi encontrado um índice de $84 \%$ de concordância entre os pesquisadores, quanto à aplicação das categorias, indicando uma confiabilidade aceitável.

\section{Resultados}

Após terem sido calculadas a frequiência e a percentagem de cada categoria, foi aplicado o Teste Mann-Witney, com a finalidade de comparar os resultados dos dois grupos. Neste teste se utiliza a média aritmética dos postos atribuídos aos valores conforme a hierarquização na seqüência geral, por se tratar de valores ordinais. Foi utilizado o pacote estatístico SPSSWIN/PC + 7.5 (Statistical Package for the Social Sciences - Personal computer Windows version 6.0). Os resultados foram os seguintes:

Tabela 2.

Enunciados e comportamentos não-verbais infantis.

\begin{tabular}{lccc|}
\hline $\begin{array}{c}\text { Enunciados e comportamentos não- } \\
\text { verbais infantis }\end{array}$ & $\begin{array}{c}\text { Crianças portadoras de } \\
\text { Síndrome de Down } \\
\text { (Média de Postos) }\end{array}$ & $\begin{array}{c}\text { Crianças normais } \\
\text { (Média de Postos) }\end{array}$ & Teste U \\
\hline Fala espontânea & 6,25 & 6,75 & 16,500 \\
Comportamento não-verbal & 6,50 & 6,50 & 18,000 \\
espontâneo & 5,83 & 7,17 & 14,000 \\
Respostas (geral) & 8,75 & 4,25 & $4,500^{*}$ \\
Não-resposta & 4,83 & 8,17 & 8,000 \\
Demonstração de afeto & 7,33 & 5,67 & 13,000 \\
Demonstração de desagrado & 7,08 & 5,92 & 14,500 \\
Observação & 6,33 & 6,67 & 17,000 \\
Continuação da atividade & 5,25 & 7,75 & 10,500 \\
Outros & & &
\end{tabular}




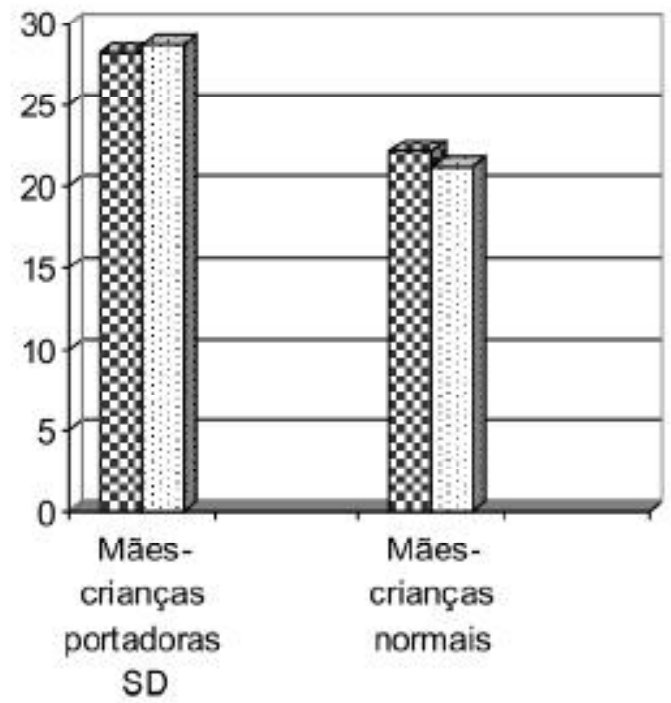

ĐS. verbal

๒S. กี-verbal

Figura 1

Proporção das sequiências verbais e não-verbais iniciadas pelas mães.

\section{Estilos de fala e ações maternas}

Dos estilos de fala materna, a única categoria que apresentou diferença significativa foi a de contato físico de ajuda, conforme mostra a Tabela 1. Este resultado indica que as mães das crianças portadoras de SD utilizaram mais comunicação não-verbal para auxiliar os filhos na realização das atividades do que as mães das crianças com desenvolvimento normal.

\section{Enunciados e comportamentos não-verbais infantis}

A Tabela 2 mostra que a categoria foi a única que teve diferença significativa entre os enunciados e comportamentos infantis. Isto significa que as crianças portadoras de SD responderam menos às solicitações de suas mães do que as crianças com desenvolvimento normal.

\section{Análises das seqüências}

A partir da análise das seqüências, foi possível observar as iniciativas de interação por parte dos membros das díades. Verificou-se uma maior frequiência desse comportamento no grupo das mães das crianças portadoras de SD, como pode ser visualizado na Figura 1.

Em relação às seqüências iniciadas pelas crianças, observou-se uma maior frequiência de início de seqüência no grupo das crianças com desenvolvimento normal, conforme demonstrado na Figura 2.

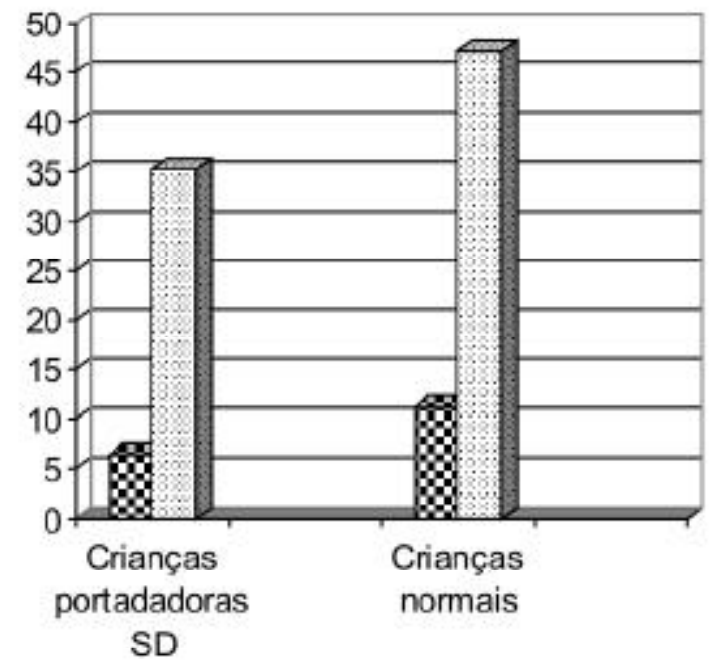

\section{QS. verbal ㄴ. ñ-verbal}

Figura 2.

Proporção das seqüências verbais e não-verbais iniciadas pelas crianças 

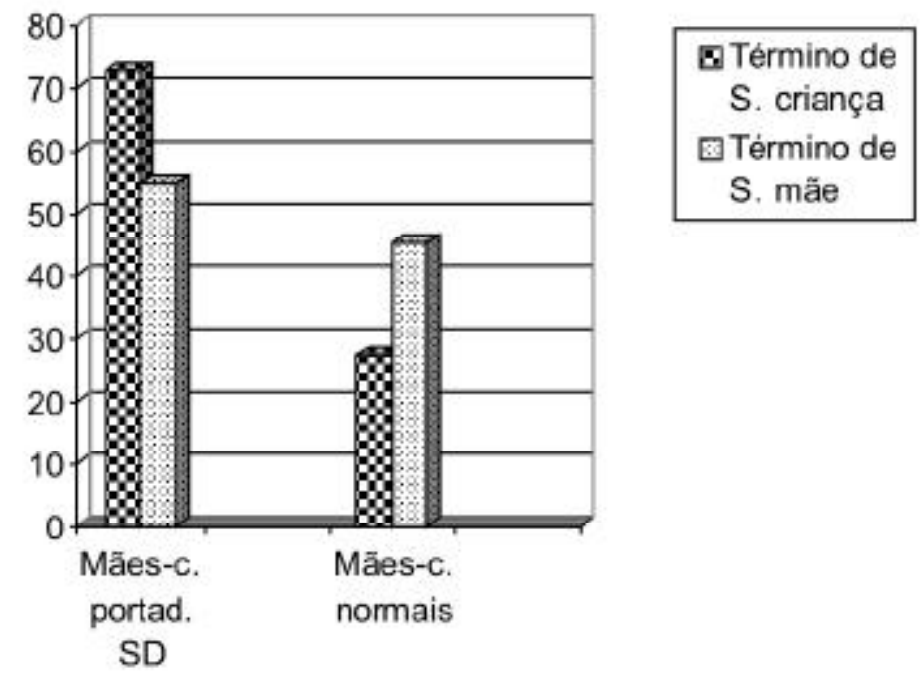

Figura 3

Proporção de término das sequiências pelas mães e pelas crianças

Em relação ao término das sequiências, verificou-se que houve uma maior frequiência desse comportamento no grupo das díades mães-crianças portadoras de SD, como pode ser visto na Figura 3.

\section{Discussão}

\section{Estilos maternos de comunicação}

Apesar de este estudo ser constituído por um número pequeno de participantes, os seus resultados apresentam alguns aspectos que devem ser considerados e que podem contribuir para a compreensão das interações mãe-criança. Um desses aspectos diz respeito aos estilos comunicativos maternos dirigidos a crianças com desenvolvimento normal e portadoras de SD, que, com exceção da categoria contato físico de ajuda, não mostraram diferença significativa entre os dois grupos. Este resultado pode ter relação com o fato de as crianças se encontrarem em um período semelhante de desenvolvimento. Esta conclusão é consistente com a literatura existente sobre o assunto, onde foi encontrado que o estilo de comunicação materna está relacionado ao nível de compreensão da criança (Conti-Ramsden \& Friel-Patti, 1986; Damast, Tamis-leMonda \& Bornstein, 1996).

Quanto ao uso de contato físico de ajuda materna, verificou-se que as mães das crianças portadoras de SD usaram mais o contato físico para ajudar os filhos a realizar atividades do que as mães das crianças com desenvolvimento normal. Este resultado é semelhante ao encontrado no estudo realizado por Pino (2000), no qual as mães das crianças portadoras de SD usaram mais comportamentos de ajuda nas interações com os filhos do que as mães de crianças com desenvolvimento normal. Esse estilo interativo pode ter relação tanto com as características específicas da criança quanto com a avaliação que a mãe faz do seu desempenho. A mãe da criança portadora de SD pode usar mais ajuda física por achar que o filho não é capaz de realizar algumas atividades sozinho. Esta avaliação pode levá-la, em alguns episódios, a impedir que o filho finalize a tarefa, seja realizando a tarefa pela criança ou introduzindo um novo tema à situação de brincadeira, como foi observado através da análise de seqüência.

Considerando-se as semelhanças nos estilos de comunicação materna, observa-se que o comportamento demonstração de afeto foi o que apresentou maior semelhança entre os dois grupos, o que pode ter relação com o desenvolvimento das crianças, uma vez que as mães tendem a modificar seu estilo de interagir em função do período de desenvolvimento em que a criança se encontra (Aimard, 1998; Snow, 1997). Como as crianças dos dois grupos se encontravam em um período de desenvolvimento correspondente, apesar de a idade cronológica ser diferente, o comportamento materno de afeto foi semelhante. Sorrisos, abraços e beijos foram os comportamentos mais presentes, e se observou que esse estilo materno de interagir foi utilizado, principalmente, para estimular ou reforçar o comportamento da criança. Portanto, pode-se sugerir que estas demonstrações de afeto materno parecem ser comuns ao período de desenvolvimento infantil que corresponde à aquisição das primeiras palavras e ao processo de aprendizagem do caminhar, já que as crianças se encontravam nesta fase de desenvolvimento. É importante ressaltar a escassez de estudos voltados para a investigação dos aspectos afetivos da interação adulto-criança portadora de SD, o que dificulta uma avaliação mais acurada da influência desses aspectos no desenvolvimento infantil.

\section{Aspectos da participação infantil}

Quanto aos enunciados e comportamentos infantis, os resultados mostraram diferença significativa apenas para a categoria não-resposta, indicando que as crianças portadoras de SD responderam menos às solicitações de suas mães do que as crianças com desenvolvimento normal. Este resul- 
tado é consistente com os dados encontrados na literatura especializada sobre o assunto, indicando que as crianças atípicas são menos responsivas às solicitações maternas do que as crianças com desenvolvimento normal (Cunningham et al.,1981; Hadley \& Rice, 1991). Porém, vale salientar que as crianças portadoras de SD podem ter respondido menos às solicitações maternas, não apenas em função das dificuldades de expressão, comuns às crianças portadoras dessa síndrome, mas também em função do tipo de interação que era desenvolvida entre a díade.

Com relação ao comportamento não-verbal espontâneo das crianças, os resultados indicaram semelhança entre os dois grupos, a qual pode ter ocorrido em função da fase de desenvolvimento lingüístico em que as crianças se encontravam, aquisição das primeiras palavras. Antes da aquisição da linguagem formal, a comunicação não-verbal constitui a principal forma de expressão da criança (Eisele \& Aram, 1997). Como no período de aquisição da linguagem inicial a criança ainda não tem o domínio da linguagem formal, a linguagem não-verbal representa a maior parte de sua comunicação, assumindo a função de complementar a fala da criança para tornar mais claro o que ela quer expressar.

\section{Seqüencias interativas}

Com a análise das seqüências interativas, foi possível observar os aspectos qualitativos da interação mãe-criança. Os comportamentos de iniciar e terminar as seqüências foram a base para verificar quais os possíveis fatores que implicariam a quebra de sequiência. Constatou-se que esta se deveu ao fato de que o início de uma seqüência sempre levava a uma mudança do foco de atenção do outro membro da díade e, conseqüentemente, seu comportamento também mudava, para poder atender às solicitações impostas pela nova situação, implicando quebra de continuidade. Analogamente, o término de uma sequiência se constituía por uma resposta não correspondente às interações do parceiro, o que, geralmente, levava à mudança de comportamento, porque o parceiro tendia a se interessar por outro tema. Isso pode indicar que as mães, principalmente as das crianças portadoras de SD, tendiam a chamar a atenção das crianças para um novo tema, sem antes explorar as brincadeiras pelas quais os filhos demonstraram interesse, o que caracteriza não-continuidade na interação. Essa situação pode ser demonstrada com o seguinte exemplo:

M: Ó JL. o carrinho, ó! (movimenta um carrinho na frente da C).

C: (pega um trenzinho).

M: O carrinho de JL. é bonito desse jeito, é? (aponta para o carrinho).

C: (solta o trem e pega o carrinho).

M: Êta, que coisa linda de mãinha! (pega um avião).

C: (movimenta o carrinho).

M: Olha JL., olha! (mostra o avião).

É possível perceber, neste exemplo, que a mãe não explorou o interesse da criança pelos brinquedos, pois quando a criança era atraída por um brinquedo, a mãe já chamava sua atenção para um outro. A não-continuidade no estilo materno de interagir não favorece o desenvolvimento da criança porque tira-lhe a oportunidade de ter uma maior participação na interação, podendo ter implicações para a aquisição da linguagem. Damast et al. (1996) afirmam que o desenvolvimento lingüístico da criança é facilitado pela adequação dos comportamentos maternos ao contexto de trocas interativas contínuas. Este aspecto foi abordado também por Salomão (1996), que enfatizou a importância da continuidade na conversação, quando as expressões do adulto dão sequiência ao tópico da fala infantil, favorecendo uma maior participação da criança na interação.

Alguns fatores, no entanto, como a idade das crianças, a presença do observador e a falta de atenção conjunta entre mãe e filho podem ter contribuído para o comportamento materno de não-continuidade. As mães podem ter solicitado a atenção das crianças para novas situações em função das características próprias dessa fase de desenvolvimento, como o interesse da criança pelo novo. A presença do observador também pode ter influenciado essa forma materna de interagir, pois as mães podem ter usado esse estilo comunicativo com o intuito de demonstrar, para o observador, as habilidades dos filhos.

Outro fator que pode ter influenciado a não-continuidade materna na interação é a falta de atenção conjunta entre a mãe e a criança. A falta de atenção conjunta não favorece o desenvolvimento da linguagem, pois contribui para um contexto menos compartilhado para a díade. É através das atividades compartilhadas que os parceiros regulam suas intenções nas interações e constroem significados. Além disso, a atenção conjunta leva o adulto a adequar seus enunciados ao foco de atenção da criança, fornecendo um input lingüístico coerente com o contexto, o que favorece a aquisição da linguagem (Barrett, 1997). Portanto, uma conduta mais adequada seria a mãe desenvolver brincadeiras partindo do foco de interesse da criança.

\section{Considerações finais}

Apesar de os estudos comparativos entre crianças atípicas e com desenvolvimento normal constituírem um aspecto de grande importância para a compreensão do processo de aquisição e desenvolvimento da linguagem, os resultados desses estudos devem ser considerados levando-se em conta algumas dificuldades relacionadas aos critérios utilizados para a equiparação da amostra, à escolha da técnica para a coleta de dados e ao tamanho da amostra, que geralmente é pequena, devido ao trabalho e ao tempo gastos na coleta e análise dos dados. Tais dificuldades podem influenciar os resultados das pesquisas e contribuir para implicações quanto à generalização dos estudos.

Neste trabalho, o fato de ter sido utilizado o vídeo para a coleta dos dados permitiu uma análise mais fidedigna porque foi possível rever as filmagens várias vezes, para uma transcrição mais minuciosa das interações mãe-criança. Além disso, o uso do sistema computacional CHILDES facilitou o pro- 
cesso de codificação e permitiu maior rapidez e precisão no processo de análise.

Quanto a sugestões para estudos futuros, deve ser destacada a importância de uma investigação mais acurada das expectativas maternas em relação às habilidades dos filhos e como essas expectativas influenciam a forma de interagir entre a mãe e a criança. Seria interessante também que se analisasse a interação da mesma mãe com o filho portador de síndrome de Down e com o filho com desenvolvimento normal que se encontre no mesmo estágio lingüístico, para se poder investigar se alguns estilos maternos se devem às características da criança ou às características da mãe.

Considerando-se os aspectos que foram observados, pode-se concluir que o presente estudo fornece alguns dados que podem favorecer a estruturação de intervenções que atendam à população estudada, podendo contribuir, ainda, para uma maior compreensão das influências da fala dirigida à criança durante a aquisição das primeiras palavras.

\section{Referências}

Aimard, P. (1998). O surgimento da linguagem na criança. Porto Alegre: Artes Médicas.

Akhtar, N., Dunham, F., \& Dunham, P. (1991). Directive interactions and early vocabulary development: the role of joint attentional focus. Journal of Child Language, 18, 41-49.

Barrett, M. (1997). Desenvolvimento lexical inicial. In P. Fletcher \& B. MacWhinney (Orgs.), Compêndio da linguagem da criança (pp. 299-321). Porto Alegre: Artes Médicas.

Bohannon, J. N., \& Stanowicz, L. (1988). The issue of negative evidence: adult responses to children's language errors. Developmental Psychology, 5, 684-689.

Braz, F. S. (2000). A fala dirigida a meninos e meninas: um estudo sobre o input materno e suas variações. Dissertação de mestrado não-publicada, Universidade Federal da Paraíba, João Pessoa.

Bruner, J. S. (1980). Early social interaction and language acquisition. In H. R. Schaffer (Org.), Studies in mother-infant interaction (pp. 271-289). New York: Academic Press.

Brunet, O., \& Lézine, I. (1981). Desenvolvimento psicológico da primeira infância. Porto Alegre: Artes Médicas.

Buckhalt, J. A., Rutherford, R. B., \& Goldeberg, K. E. (1978). Verbal and nonverbal interaction of mothers with their Down's syndrome and nonretarded infants. American Journal of Mental Deficiency, 82, 337-343.

Buium, N., Rynders, J., \& Turnure, J. (1974). Early maternal linguistic environment of normal and Down's syndrome language learning children. American Journal of Mental Deficiency, 79, 52-58.

Chapman, R. S. (1997). Desenvolvimento da linguagem em crianças e adolescentes com síndrome de Down. In P. Fletcher \& B. MacWhinney (Orgs.), Compêndio da linguagem da criança (pp. 517-533). Porto Alegre: Artes Médicas.

Cicchetti, D., \& Sroufe, L. A. (1976). The relationship between afective and cognitive development in Down's syndrome infants. Child Development, 47, 920-929.
Conti-Ramsden, G., \& Dykins, J. (1991). Mother-child interactions with languageimpaired children and their siblings. British Journal of Disorders of Communication, 26, 337-354.

Conti-Ramsden, G., \& Friel-Patti, S. (1986). Mother-child dialogues: considerations of cognitive complexity for young language learning children. British Journal of Disorders of Communication, 21, 245-255.

Cunningham, C., Reuler, E., Blackwell, J., \& Deek, J. (1981). Behavioral and linguistic developments in the interactions of normal and retarded children with their mothers. Child Development, 52, 62-70.

Damast, A. M., Tamis-LeMonda, C. S., \& Bornstein, M. H. (1996). Motherchild play: sequential interactions and the relation between maternal beliefs and behaviors. Child Development, 67, 1752-1766.

Demetras, M., Post, K., \& Snow, C. (1986). Feedback to first language learners: the role of repetitions and clarification questions. Journal of Child Language, 13, 275-292.

Eisele, J. A., \& Aram, D. M. (1997). Desenvolvimento lexical e gramatical em crianças com dano hemisférico precoce: uma visão transversal do nascimento até a adolescência. In P. Fletcher \& B. MacWhinney (Orgs.), Compêndio da linguagem da criança (pp. 535-554). Porto Alegre: Artes Médicas.

Fischer, M. A. (1987). Mother-child interaction in preverbal children with Down syndrome. Journal of Speech and Hearing Disorders, 52, 179-190.

Garton, A. F. (1992). Social interaction and the development of language and cognition. Hillsdale: Lawrence Erlbaum.

Hadley, P. A., \& Rice, M. L. (1991). Conversational responsiveness of speech and language-impaired preschoolers. Journal of Speech and Hearing Research, $34,1308-1317$

MacWhinney, B. (1997). Análise computadorizada das interações. In P. Fletcher \& B. MacWhinney (Orgs.), Compêndio da linguagem da criança (pp. 131150). Porto Alegre: Artes Médicas.

Nunes, L. R. P., Cunha, A. C. B., \& Nogueira, D. S. (1993). Facilitando a aquisição da linguagem funcional em criança de creche com atraso de desenvolvimento. Arquivos Brasileiros de Psicologia, 45, 49-76.

Pine, J. M. (1992). Maternal style at the early one-word stage: re-evaluating the stereotype of the directive mother. First Language, 12, 169-186.

Pino, O. (2000). The effect of context on mother's interaction style with Down's syndrome and typically development children. Research in Developmental Disabilities, 21, 329-346.

Salomão, N. M. R., \& Conti-Ramsden, G. (1994). Maternal speech to their offspring: SLI children and their younger siblings. Scandinavian Journal of Logopedios and Phonology, 19, 11-17.

Salomão, N. M. R. (1996). Interaction between mothers and children with specific language impairment: a longitudinal study. Tese de doutorado nãopublicada, University of Manchester, Reino Unido.

Sigolo, S. R. R. L. (1996). Trocas interativas entre mãe e criança com atraso de desenvolvimento: Um sistema de análise. Temas em Psicologia, 1, 33-43.

Snow, C. E. (1972). Mothers' speech to children learning language. Child Development, 43, 549-565.

Snow, C. E. (1997). Questões no estudo do input: sintonia, universalidade, diferenças individuais e evolutivas, e causas necessárias. In P. Fletcher \& B. MacWhinney (Orgs.), Compêndio da linguagem da criança (pp. 153-163). Porto Alegre: Artes Médicas.

Tomasello, M., \& Todd, J. (1983). Joint attention and lexical acquisition style. First Language, 4, 197-212. 
Maria dos Prazeres Vieira da Silva é mestra em Psicologia Social pela Universidade Federal da Paraíba. Nádia Maria Ribeiro Salomão, doutora em Psicologia pela Manchester University, Reino Unido, é professora da Universidade Federal da Paraíba, PB.

Endereço para correspondência: Departamento de Psicologia, Programa de Mestrado em Psicologia Social. Universidade Federal da Paraíba, Campus I, Cidade Universitária, 58059-900, João Pessoa, PB. Tel, (083)2167006. E-mail: mapvis@ig.com.bre nmrs@uol.com.br. 


\section{APÊNDICE A}

Características dos participantes

Quadro 1.

Características das crianças portadoras de Síndrome de Down e de suas mães.

\begin{tabular}{|c|c|c|c|c|c|c|c|}
\hline \multicolumn{5}{|c|}{ Criança } & \multicolumn{3}{|c|}{ Mãe } \\
\hline $\mathbf{N}^{0}$ & Idade & Sexo & $\begin{array}{l}\text { Número de } \\
\text { irmãos }\end{array}$ & $\begin{array}{l}\text { Ordem de } \\
\text { nascimento }\end{array}$ & Idade & Escolar. & Profis. \\
\hline 1 & 19 meses & fem. & 3 & $4^{a}$ & 45 anos & $3^{\circ} \mathrm{grau}$ & Psicóloga \\
\hline 2 & 23 meses & masc & 3 & $3^{a}$ & 31 anos & $1^{\circ}$ grau & $\begin{array}{c}\text { Dona de } \\
\text { casa }\end{array}$ \\
\hline 3 & 18 meses & fem. & 1 & $2^{a}$ & 39 anos & $2^{\circ}$ grau & $\begin{array}{l}\text { Auxiliar } \\
\text { admin. }\end{array}$ \\
\hline 4 & 18 meses & masc & 2 & $3^{a}$ & 37 anos & $3^{\circ} \mathrm{grau}$ & Odont \\
\hline 5 & 18 meses & masc & 0 & $1^{a}$ & 22 anos & $4^{a}$ série & $\begin{array}{c}\text { Dona de } \\
\text { casa }\end{array}$ \\
\hline 6 & 18 meses & fem & 1 & $2^{a}$ & 43 anos & $3^{\circ} \mathrm{grau}$ & Bancária \\
\hline
\end{tabular}

Quadro 2.

Características das crianças com desenvolvimento normal e de suas mães.

\begin{tabular}{|c|c|c|c|c|c|l|l|}
\hline \multicolumn{9}{|c|}{ Criança } & \multicolumn{2}{c|}{ Mãe } \\
\hline$N^{\circ}$ & Idade & Sexo & $\begin{array}{c}\text { Número } \\
\text { de } \\
\text { irmãos }\end{array}$ & $\begin{array}{c}\text { Ordem de } \\
\text { nascimento }\end{array}$ & Idade & Escolar. & Profis. \\
\hline 1 & 12 meses & masc. & 2 & $3^{\mathrm{a}}$ & 32 anos & $4^{\mathrm{a}}$ série & Comerciante \\
\hline 2 & 12 meses & fem. & 0 & $1^{\mathrm{a}}$ & 28 anos & $3^{\circ}$ grau & $\begin{array}{c}\text { Prof } \\
\text { Regular }\end{array}$ \\
\hline 3 & 12 meses & fem. & 2 & $3^{\mathrm{a}}$ & 28 anos & $3^{\circ}$ grau & Nutricionista \\
\hline 4 & 13 meses & fem. & 0 & $1^{\mathrm{a}}$ & 42 anos & $3^{\circ}$ grau & Prof. Univ. \\
\hline 5 & 13 meses & masc. & 0 & $1^{\mathrm{a}}$ & 26 anos & $2^{\circ}$ grau & Oper. caixa \\
\hline 6 & 12 meses & masc. & 0 & $1^{\mathrm{a}}$ & 21 anos & $2^{\circ}$ grau & Recepcionista \\
\hline
\end{tabular}




\section{APÊNDICE B}

\section{Definição das categorias}

I . Categorias referentes aos enunciados e comportamentos não-verbais da mãe, dirigidos à criança

1. Diretivos (DI) - diz respeito aos enunciados maternos que têm como função chamar a atenção, regular ou dirigir as verbalizações ou comportamentos da criança;

1a. DI: Instrução precisa (DI:IP) - a mãe diz para a criança o que fazer, seja nomeando objetos ou descrevendo suas características;

1b. DI: Instrução imprecisa (DI:II) - a mãe expressa para a criança o que fazer, sem nomear os objetos ou descrever suas características;

1c. DI: Solicitação de atenção (DI:SA) - a mãe chama a atenção da criança, manuseando algum brinquedo, pronunciando o nome da criança ou utilizando alguma palavra que desperte o seu interesse por algo;

1d. DI: Repetição (DI:R) - a mãe pede que a criança repita uma palavra ou uma ação;

2. Requisições (REQ) - enunciados maternos que solicitam da criança respostas verbais ou não-verbais relativas a objetos, situação ou ação;

2a. REQ: Solicitação de resposta (REQ:SR) - a mãe faz uma pergunta para a criança solicitando uma resposta verbal ou nãoverbal relativa a uma situação ou a uma atividade em que estão envolvidas;

2b. REQ: Sugestão (REQ:SU) - a mãe pergunta algo ou faz uma declaração através da qual propõe uma possível ação;

3. Feedback $(\mathrm{FE})$ - enunciados maternos de aprovação, desaprovação ou correção, que têm como função responder às verbalizações ou ações da criança;

3a. FE: Aprovação (FE:A) - resposta, verbal ou não-verbal, aprovando o enunciado ou ação da criança;

3b. FE: Desaprovação (FE:D) - resposta verbal ou não-verbal indicando que o enunciado ou ação da criança não foi apropriado;

3c. FE: Correção (FE:C) - enunciado que se segue a uma verbalização ou comportamento incorreto da criança, atribuindolhe a forma correta. Geralmente, a mãe solicita que a criança repita a forma correta;

3d. FE: Resposta (FE-R) - verbalizações da mãe em resposta a questões formuladas pela criança;

4. Informar (IF) - enunciados maternos que fornecem informações para a criança com o objetivo de contribuir para o desempenho de atividades, seja nomeando objetos, demonstrando ou descrevendo uma ação;

4a. IF: Nomear (IF:N) - a mãe apenas nomeia o objeto para a criança;

4b. IF: Descrever ou demonstrar uma ação (IF:DDA) - a mãe descreve ou demonstra uma ação com o objetivo de auxiliar a criança no desempenho de determinada atividade;

5. Comentários(COM) - enunciados da mãe sobre as suas próprias ações ou sobre o comportamento da criança e que podem ser dirigidos ao observador;

6. Contato físico de ajuda (CFA) - a mãe ajuda a criança, segurando suas mãos ou mantendo algum tipo de contato físico, com o intuito de direcionar a ação da criança para a realização de uma determinada tarefa. Está incluído, nesta categoria, o apoio que a mãe oferece à criança quando segura o objeto para a mesma manusear;

7. Demonstração de afeto materno (DA:M) - comportamentos não-verbais da mãe que expressam afeto, como sorriso, abraço, beijo e carícia;

8. Outros (OUT) - enunciados ou comportamentos não-verbais que não se incluem em nenhuma das categorias definidas acima.

II. Categorias referentes aos comportamentos verbais e não-verbais da criança

1. Fala espontânea (FA:E) - verbalização da criança que não é precedida por uma pergunta ou não é uma imitação de um enunciado prévio da mãe; 
2. Comportamento não-verbal espontâneo (CNV:E) - comportamento não-verbal da criança que não é precedido por uma ação ou enunciado da mãe;

3. Respostas $(\mathrm{R})$ - respostas verbais e não-verbais da criança aos enunciados maternos;

3a. Resposta verbal adequada (R:VA) - quando a resposta verbal da criança a um enunciado prévio da mãe é correta ou apropriada;

3b. Resposta verbal inadequada (R:VI) - quando a resposta verbal da criança a um enunciado prévio da mãe não é correta ou apropriada;

3c. Resposta não-verbal adequada (R:NVA) - quando a resposta não-verbal da criança a um enunciado prévio da mãe é correta ou apropriada;

3d. Resposta não-verbal inadequada (R:NVI) - quando a criança responde ao enunciado prévio da mãe de forma incorreta ou inadequadamente;

3e. Não resposta (NR) - diante de uma pergunta, a criança não responde, verbalmente, nem não-verbalmente;

4. Demonstração de afeto (DA:C) - toda manifestação de sentimento não-verbal da criança que expressa afeto, como sorriso, abraço, beijo e carícia;

5. Demonstração de desagrado (DD:C) - verbalizações ou comportamentos não-verbais da criança que expressam conotação de desagrado, como choro, resmungo e gestos de desagrado;

6. Observação (OBS) - diante de uma ação ou de uma informação dada pela mãe, a criança permanece olhando para a mãe ou para o objeto ao qual ela se refere. Esta categoria só foi atribuída quando a observação não foi acompanhada de verbalização pela criança;

7. Continuação de atividade pela criança $(\mathrm{CAC})$ - comportamentos não-verbais da criança que dão seqüência à atividade que foi iniciada em resposta a um enunciado ou comportamento não-verbal materno e que não constituem uma resposta direta às verbalizações ou ações da mãe;

8. Outros (OUT) - verbalizações ou comportamentos não-verbais da criança que não se incluem em nenhuma das categorias definidas acima. 


\section{APÊNDICE C}

\section{Definição das seqüelas interativas}

1. Seqüência iniciada pela mãe (SI:M) - verbalizações (SI:VM) ou comportamentos não-verbais da mãe (SI:NVM), que introduzem um novo tema, provocando mudança no curso da interação. Foi considerado como tema o "objeto" ou a "ação" que se tornava foco de atenção para os membros da díade durante a interação;

2. Seqüência iniciada pela crainça (SI:C) - verbalizações (SI:VC) ou comportamentos não-verbais da criança (SI:NVC), que introduzem um novo tema, provocando mudança no curso da interação;

3. Término de uma seqüência (TS) - enunciados ou comportamentos não-verbais que levam à mudança do tema ou do curso da interação. Só foram codificados os enunciados ou comportamentos não-verbais da mãe (TS:M) ou da criança (TS:C) que terminaram uma seqüência sem que tivessem dado inicio a uma nova sequiência. 